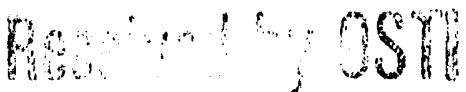

NOV 161990
SAND- $-90-1828 \mathrm{C}$

DE91 002697

SAND90-1828 $\mathrm{AC}$

Unlimited Release

Printed October 1990

\title{
IN-SITU DERIVATIVE CYCLIC VOLTABSORPTOMETRIC STUDIES \\ ON
}

POLY - 3-METHYLTHIOPHENE

S. N. Hoier*, D. S. Ginley*, and Su-Moon Park**

*Sandia National Laboratories, Albuquerque, New Mexico 87185

$\star *$ Department of Chemistry, University of New Mexico, Albuquerque,

New Mexico 87131

\section{DISCLAIMER}

prepared as an account of work sponsored by an agency of the United States the United States Government nor any agency thereof, nor any of their Government. Neither the Uniry, express or implied, or assumes any legal hability or roduct, or employees, makes any warramy, expres or usefulness of any information, apparalus, produch. Referbility for the accurac', comples that its use would not infringe privately owned righe, trademark, process disclosed, or represents inercial product, process, or service by trade name, lre recomence herein to any specific commenol necessarily constitute or imply its endorem. The views manufacturer, or otherwise does not neces States Government or any agency thereof. The of the mendation, or favoring by the United Stan herein do necessarily state or reflect those of the

and opinions of authors expressed herates Government or any agency thereof. 


\section{IN-SITU DERIVATIVE CYCLIC VOLTABSORPTOMETRIC STUDIES \\ ON \\ POLY - 3 - METHYLTHIOPHENE}

S. N. Hoier*, D. S. Ginley*, and Su-Moon Park**

* Sandia National Laboratories, Albuquerque, New Mexico 87185

$\star \star$ Department of Chemistry, University of New Mexico, Albuquerque,

New Mexico 87131

\section{ABSTRACT}

Spectroscopic behavior of poly-3-methylthiophene (P3MT) has been studied employing derivative cyclic volt-absorptometric (DCVA) techniques. In the DCVA technique, the derivative absorption signal $(\mathrm{d} A / \mathrm{d} t)$ is recorded as a function of the applied potential. The $\mathrm{d} A / \mathrm{d} t$ signals, the spectroscopic analog of electrochemical currents in cyclic voltammetry, are capable of monitoring the potential dependency for the absorption band effectively discriminating against nonfaradaic signals. The DCVA studies on the P3MT system show that the neutral form of P3MT, absorbing at $490 \mathrm{~nm}$ (at less than $0.3 \mathrm{~V}$ vs. $\mathrm{Ag}$ ), changes to the radical cation form, which absorbs at $760 \mathrm{~nm}$. Initially, the formation of the radical cation goes through an isosbestic point, indicating that the conversion of the neutral to radical (polaron) form is chemically reversible. However, upon increasing the electrode potential, the rate of the radical formation at $760 \mathrm{~nm}$ starts to decrease, with the formation of another band at about $1250 \mathrm{~nm}$, attributable to a quinoid (bipolaron) form. This trend begins above about $0.6 \mathrm{~V}$, shifting to a more positive voltage as the thickness of the film grows. This observation indicates that the electrochemical conversion of the neutral to radical form, followed by the quinoid form, is a slow process controlled by the diffusion of counter ions through the film. In-situ conductivity measurements as a function of applied potentials and chronoamperometric results support the observed spectroscopic behavior.

\section{INTRODUCTION}

Interest in conducting polymers was stimulated by Little's suggestion of superconductivity in organic materials in the mid-1960's [1a]. Since Shirakawa, MacDiarmid and cowurkers demonstrated the semiconducting and metallic properties of polyacetylene, a linear corijugated organic polymer, in 1977 [1b], a surge of interest in this class of materials has been shown in the literature resulting in a number of review articles, books, and symposium volumes [2-8]: Of the many different types of organic conducting polymers, polythiophene and its substituted analogs appear to offer greater environmental stability with a more rigid, yet similar, structure to polyacetylene. The higher stability may accrue from the large electronic shell of the sulfur atom, making the free carrier available more readily at lower chemical potentials.

Preparations of polythiophenes with various substituted monomer units have been reported, and their physical/chemical properties have been evaluated [9-14]. UVvis [15a, 15b] and infrared absorption spectra [10a, 10b], as well as morphological studies $[9,10 a]$ of electrochemically prepared polythiophenes have recently been reported. These studies show that the conducting polymer has a porous network structure. The oxidized form is conductive, whereas the reduced 
form is semiconducting. In this study, we use a combination of cyclic voltammetry and spectrometric measurements to study the doping behavior of poly3-methylthiophene, a substituted polythiophene.

\section{EXPERIMENTAL}

Experiments were carried out in propylene carbonate (PC, reagent grade) with lithium perchlorate (reagent grade) as the supporting electrolyte. The 3methylthiophene monomer obtained from Aldrich(99+8) was used as received. The polymer films were grown on working electrodes, gold or platinum, with a silver wire pseudo-reference electrode in a solution containing $0.50 \mathrm{M}$ supporting electrolyte and approximately $1.0 \mathrm{M}$ monomer. Electro-polymerization was done galvanostatically at $175 \mu \mathrm{A} / \mathrm{cm}^{2}$ with a platinum electrode, or by potentiostatically scanning between 0.0 and 1.8 volts with the gold interdigitated grid electrode (Fig. 1.) in $\mathrm{PC} / \mathrm{LiClO}_{4}$ [16]. Scan rates were typically $50 \mathrm{mV} / \mathrm{sec}$, unless specified otherwise.

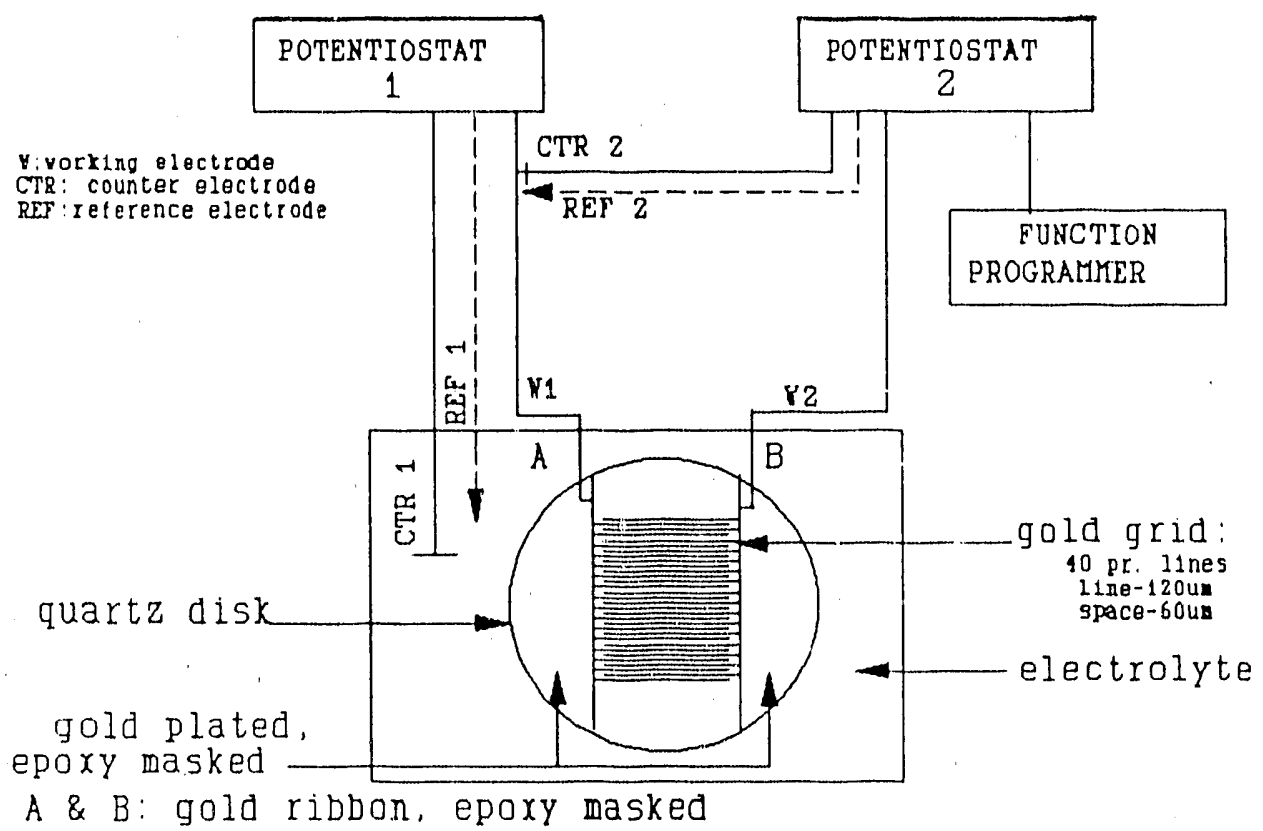

Fig. 1. Drawing of the electrode and cell configuration for conductivity experiments.

The near normal incidence reflectance spectroelectrochenistry (NNIRS) setup has been described elsewhere [17]. A Princeton Applied Research (PAR) Model 173 potentiostat and PAR 175 function generator were used to control potentials at the working, electrode. The cell consisted of a platinum working electrode, which was polished to a mirror finish with $1 \mu \mathrm{m}$ METADI ${ }^{\circledR}$ polishing compound from Buehler Ltd., a silver wire pseudo-reference electrode, and a spiral platinum counter electrode. Data acquisition and stepper motor control to drive the monochromator were accomplished by using an IBM-X'T computer with a Keithley 570 interface board. A film of $0.04-\mu \mathrm{m}$ thickness was grown galvanostatically at $40 \mu \mathrm{A}$ on a $0.23-\mathrm{cm}^{2}$ platinum electrode.

For the conductivity studies, films of $1 \mu \mathrm{m}$ and $5 \mu \mathrm{m}$ were grown on a quartz electrode with interdigitated $120-\mu \mathrm{m}$ gold lines and $60 \mu \mathrm{m}$ spacing as shown in Fig. 1 by potentiastatically scanning from 0 to 1.8 volts and holding at $1.7 \mathrm{~V}$ vs. silver until the desirable thickness was obtained. The interdigitated 
electrode was fabricated by electroplating in a Dequest 2000 gold cyanide bath on a quartz disk, one inch in diameter and $1 / 16$ inch thick. Leads $A$ and $B$ in Fig. 1 were connected together as the working electrode during film growth. Films were studied in three concentrations of $\mathrm{LiClO}_{4}$ in $\mathrm{PC}(0.5,0.05$ and 0.005 M.) Conductivity measurements were made by holding the film at a given potential with one potentiostat, and recording the current-potential (I-V) curves with a second potentiostat by 'scanning from 0 to $110 \mathrm{mV} v \mathrm{~s}$. Ag at $10 \mathrm{mV} / \mathrm{s}$.

\section{RESULTS AND DISCUSSION}

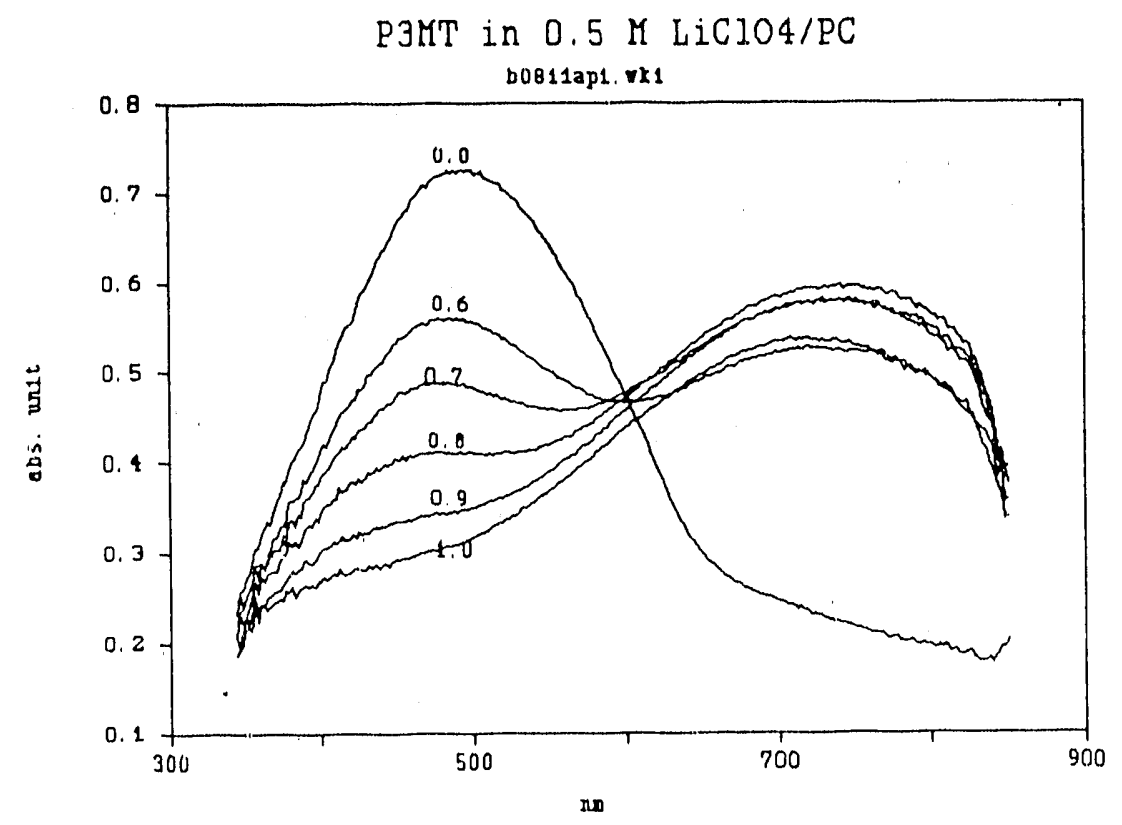

Fig. 2. Visible spectra of P3MT obtained with NNIRS.

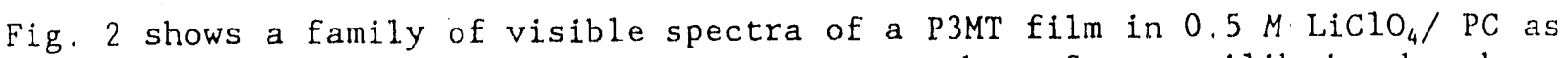
a function of applied potential. Spectra are taken after equilibrium has been reached at a given potential. The absorption maximum observed at about $480 \mathrm{~nm}$ is attributed to the $\pi-\pi^{*}$ transition of the basic thiophene aromatic structure. The broad band at $750 \mathrm{~nm}$ is due to the polaron absorption in the oxidized polymer. Isosbestic points are observed at about $640 \mathrm{~nm}$. An isosbestic point indicates a fixed stoichiometric relationship between the two states, and supports the high chemical reversibility of the doping process. This reversible doping-undoping is a unique characteristics of polyene (polymer with conjugated $\pi$ bond) conducting polymers. An isosbestic point is obtained between 0.0 and 0.6 $\mathrm{V}$. Another isosbestic point is obtained between 0.7 and $0.8 \mathrm{~V}$. At above $0.8 \mathrm{~V}$, absorbarice of the film is reduced; this indicates film degradation (as shown at 0.9 and $1.0 \mathrm{~V}$ ). These behavior indicates a total of two process occurs sequentially before the film degrades. The spectra of the same film in $0.05 \mathrm{M}$ and $0.005 \mathrm{M}$ cf $\mathrm{LiClO}_{4}$ are essentially the same (Spectra not shown).

The cyclic voltammograms (CV's) of a $0.04-\mu \mathrm{m}$ P3MT film in Fig. 3 show changes as a function of the $\mathrm{LiClO}_{4}$ concentrations. The anodic peaks are not visible; however, CVs with less noise have been obtained with thicker films [15a]. The ( $V$ signal increases, as well as the noise level decreases, as the $\mathrm{LiClO}_{4}$ concentration decreases. The DCVA data is a plot af derivative absorbance $(d A / d t)$ signal as a function of the scanning potential [18-19]. Here $A$ represents absorbance signal recorded at a given wavelength and $t$ is time. The DCVA plots show the voltammetric behavior of a species absorbing photons at a given wavelength. This eliminates the interference signals originating from both nonfaradaic and some faradaic processes. Signals from the faradaic (redox) 


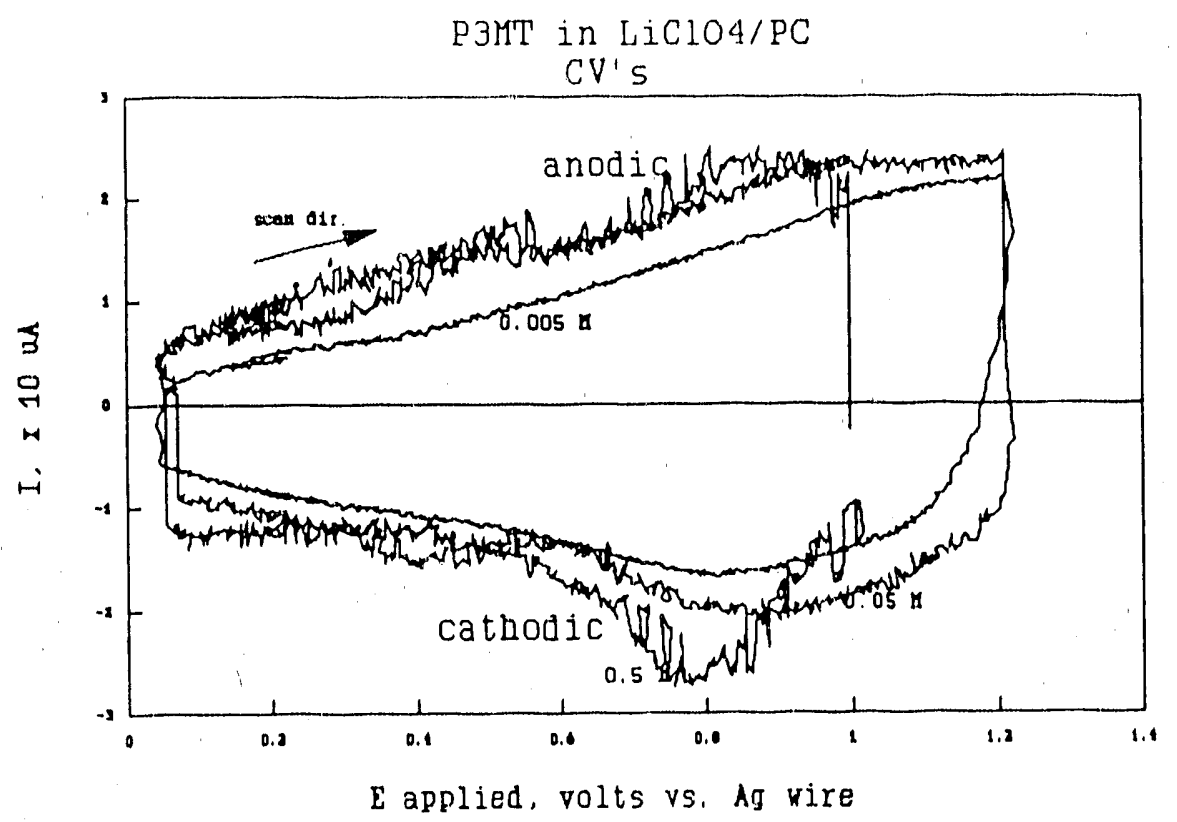

Fig. 3. CV'S of P3MT in $0.5 \mathrm{M}, 0.05$ and $0.005 \mathrm{LiC1O} / \mathrm{PC}$.

processes for a species which does not absorb photons at this wavelength are eliminated.

Figs. $4 \& 5$ show the DCVA plots at 750 and $482 \mathrm{~nm}$ respectively. The effect of concentration of $\mathrm{LiClO}_{4}$ is obvious in Fig. 4 at $750 \mathrm{~nm}$. The first oxidized species starts to form as the potential is scanned to the anodic region, showing its peak maximum at $0.2 \mathrm{~V}$ in $0.5 \mathrm{M} \mathrm{LiClO}_{4}$ and at $0.4 \mathrm{~V}$ in $0.05 \mathrm{M}$, then at $0.6 \mathrm{~V}$ in $0.005 \mathrm{M}$. Similarly, the point where the first oxidized species shows depletion, where $\mathrm{d} A / \mathrm{d} t$ equals to zero, also shifts to a more positive potential as the concentration of the supporting electrolyte decreases. Perhaps this is caused by the additional overpotential required to oxidize the film as the conductivity of the supporting electrolyte decreases. The positive shift in CV

p3mt in LiCLO4/PC. at $750 \mathrm{na}$

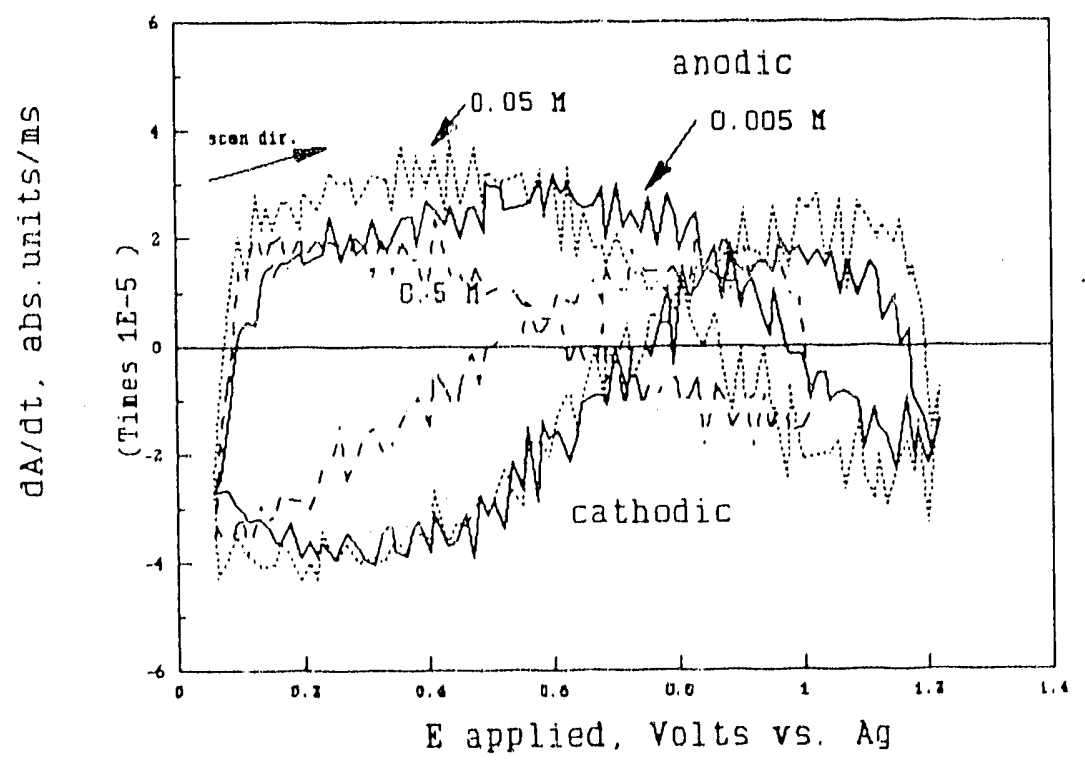

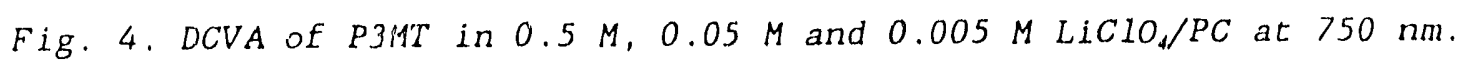




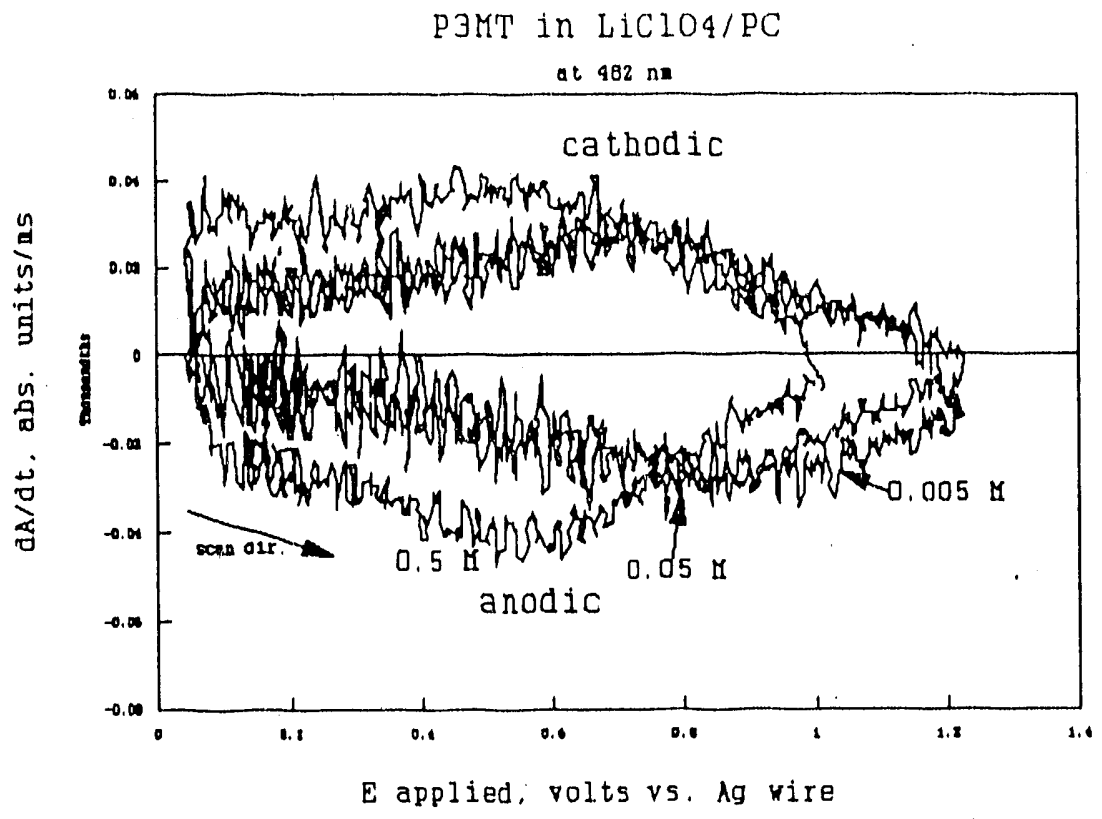

Fig. 5. DCVA of P3MT in $0.5 \mathrm{M}, 0.05$ and $0.005 \mathrm{M} \mathrm{LiClO} / \mathrm{PC}$ at $482 \mathrm{~nm}$.

peak potentials is also observed as a function of film thickness [20]. As the thickness increases, the time of diffusion of counter ions through the thickness increases as well. This phenomenon indicates that the redox reaction in the film occurs under diffusion control of the counter ions.

The DCVA curves at $482 \mathrm{~nm}$ (Fig. 5) show that the undoped species is depleted as the applied potential becomes more positive. The concentration of the species absorbing at $750 \mathrm{~nm}$ (Fig. 4) shows an increase at the expense of this species until the potential gets to $0.2-0.6 \mathrm{~V}$, depending on the thickness of the film. At this potential, a more oxidized species absorbing at $1250 \mathrm{~nm}$ (the bipolaron) begins to be generated at the expense of the first oxidized species [15]. This indicates that more than one processes occurs at this potential. However, only one peak is observed in the CV. Unfortunately, the DCVA signal at $1200 \mathrm{~nm}$ was not recorded due to the limitation of the present hardware.

The results of the in-situ conductivity experiments, for a $1-\mu \mathrm{m}$ thick film during the growth areshown in Fig. 6. The current flowing through the interdigitated $\mathrm{film}$ increases as the applied potential increas, from -0.6 to $0.8 \mathrm{~V}$. Then the current remains at the same level until $1.6 \mathrm{~V}$. In the presence of the 3methylthiophene monomers, the current increases as the film grows.

Similar data have been collected for a film of $5 \mu \mathrm{m}$ thickness in $0.5,0.05$, and $0.005 \mathrm{M} \mathrm{LiClO}_{4}$. Small increases in currents are observed as the concentration of the supporting electrolyte increases. Since conductivity is directly proportional to the current, the conductivity of the film increases from $-.6 \mathrm{~V}$ to 0.8 and is maintained from 0.8 to $1.8 \mathrm{~V}$ in the absence of monomer. However, in the presence of monomers, the conductivity increases at $1.6 \mathrm{~V}$ when electropolymerization occurs.

\section{CONCLUSION}

This report has demonstrated the utility of the DCVA and related techniques in studying P3MT. From the observations reported in this study, we can draw the following conclusions: 
(1) The oxidation of the P3MT film is controlled by diffusion of counter ions. This is illustrated by the shifts in DCVA peak signals in the anodic direction at $482 \mathrm{~nm}$ as the film thickness increases.

(2) It has been shown by NNIRS visible spectra and DCVA neasurements that what appears as a single CV peak consists of currents arising from more than one redox processes.

(3) In-situ conductivity measurements irdicate that the generation of bipolarons does not change the conductivity of the film. In polyaniline, the conductivity of the film decreases as the film becomes bipolaronic [16].

\section{ACKNOWLEDGEMENT}

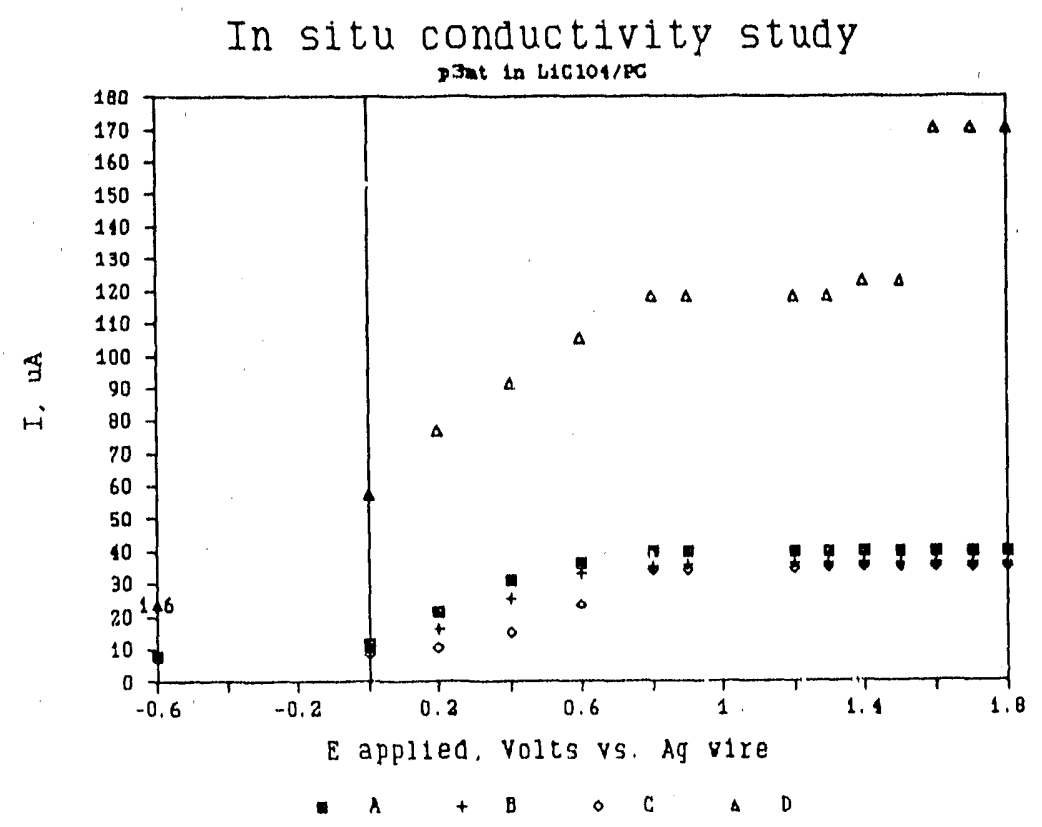

Fig. 6. Results of current vs. E applied of P3MT film: $5 \mu \mathrm{m}$ in (A) 0.5 , (B)

$0.05 \&$ (C) $0.005, \mathrm{MLiC10} / \mathrm{AC} ;$ (D) $1 \mu \mathrm{m}$ as in (A).

We wish to thank M. B. Sinclair and M. A. Valdez, Sandia National Laboratories, for the fabrication of the electrode for the conductivity experiment. This work was supported by the United States Department of Energy under Contract DEACO476 DP00789.

\section{REFERENCES}

1(a).W. A. Little, Phys. Rev. 134A, 1416(1964); 1(b). H. Shirakawa, E. J. Louis, A. G. MacDiarmid, C.K. Chiang, and A. J. Heeger, J. Chem. Soc., Chem. Commun. 1977, 578 .

2. C. I. Simmionescu and V. Percec, Prog. Polum. Sci., 8, 133 (1982).

3. R. H. Baughman, J. L. Bredas, R. R. Elsenbaumer, and L. W. Shacklette, Chem. Rev., 82, 209 (1982)

4. A. O. Patil, A. J. Heeger, and F. Wudl, Chem. Rev, 88, 183 (1988)

5. R. B. Seymour, Editor, Conductive Polymer, Plenum Press, New York (1981)

6. J. C. W. Chien, Polyacetylene-Chemistry, Physics, and Material Science, Academic Press, New York (1984)

7. A. J. Epstein and E. M. Conwe11, Editors, Proceedings International Conf. LowDim. Conductors, Mo1. Crysl. Liq. Cryst., 83, 1033-1384 (1982) 
8. M. Aldissi, Editor, Proceedings of the International Conference on Science and Technology of Synthetic Metals (ICSM '88), Elsevier Sequoia S.A. Lausanne (1989)

9. R. J. Waltman, J. Bargon, and A. F. Diaz, J.phys. Chem, , 87, 1459 (1983)

10 (a). S. Tanaka, M. Sato, and K. Kaeriyama, Makromol. Chem, 185, 1295 (1984);

10(b). Etemad, S; Heeger, A. J.; MacDiarmid A. G. Annu, Rev. Phys. Chem., $1982,33,443$.

11. K. Kaneto, s. Ura, K. Yoshino, and Y. Inuish, Jpn. J, App1, Phys, 23, L189 (1984)

12. M. Sato, S. Tanaka, and K. Kaeriyama, J, Chem, Soc.. Chem. Commun, 1986, 873

13. K. Y. Jen, G. G. Miller, and R. L. Elsenbaumer, J, chem. Soc . Chem. Commun. $\underline{1986}, 1346$

14. S. Hotta, S. D. Rughooputh, A. J. Heeger, and F. Wudl, Macromolecules, 20, 212 (1987)

15(a). S. N. Holer, D. S. Ginley, and S. -M. Park, J. Electrochem, Soc, 135, 91 (1988); (b). Kaneto,K.; Kohno, Y; Yoshino, K. Mol, Cryst. Liq. Crys. $1985,118,217$.

16. E. W. Paul, A. J. Ricco, and M. S. Wrighton, J. Phys, chem., 89, 1441 (1985)

17. C. -H. Pyun and S. -M Park, Anal. Chem., 58, 251 (1986)

18. D. E. Stilwell and S. -M. Park, J. Electrochem. Soc, 136, 427 (1989)

19 (a). C. Zhang and S. -M. Park, Anal. Chem., 60, 1639 (1988); (b). C. Zhang and S. -M. Park, Bu11. Korean Chem, Soc, 10, 302(1989).

20. S. N. Hoier and S. -M. Park, $4^{\text {th }}$ Int, SAMPE Electronics Conf., 4, 357 (1990). 

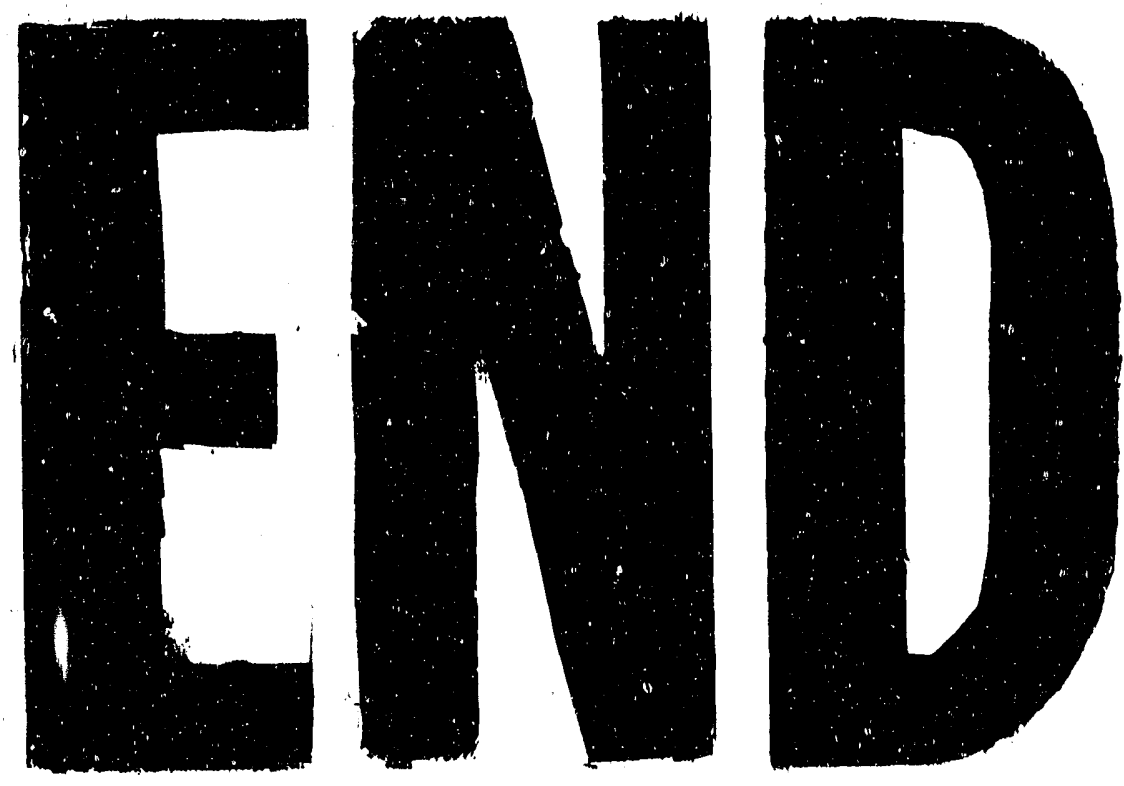

4
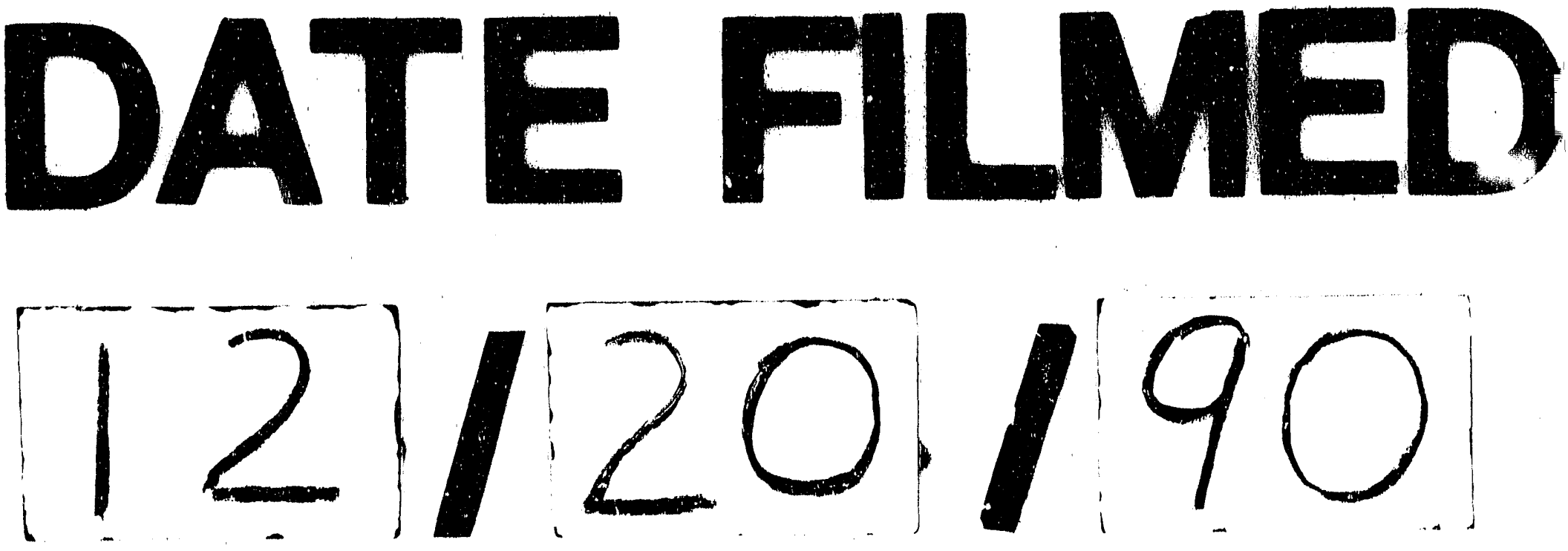
